\title{
MOTIF BATIK DI KAMPUNG WISATA BATIK KEMBANG TURI KOTA BLITAR
}

\author{
Jeng Oetari ${ }^{1}$ \\ (Jurusan Kriya Tekstil Dan Mode, Fakultas Industri Kreatif \\ Universitas Telkom, oetariiajeng@gmail.com, oetariiajeng@student.telkomuniversity.ac.id, 082298900959) \\ Morinta Rosandini \\ (Jurusan Kriya Tekstil Dan Mode, Fakultas Industri Kreatif \\ Universitas Telkom, morintarosandini@telkomuniversity.ac.id, 082116610768)
}

\begin{abstract}
Batik Kembang Turi, Blitar was present in 2018 as an embodiment of batik preservation in the City of Blitar. The Blitar Turi Batik Blitar Gallery has become one of the centers of making batik, has succeeded in empowering the surrounding community to produce batik with Blitar's distinctive characteristics. But until now not many people outside the city of Blitar know the beauty and uniqueness of Batik Kembang Turi Blitar, even though there is a lot of potentials that can be developed to be able to increase the strength of the characteristics of Kembang Turi Blitar Batik. The results of this study in the form of data from 17 batik motifs that have the characteristics of the main motifs, the Kembang Turi motif in combination with the Koi, Gendang, Bung Karno, and Lotus motifs that are characteristic of the city of Blitar. The distinctive color that is used on Kampung Batik Kembang Turi batik, namely bright colors, red colors, green and black are the hallmarks of Batik Kembang Turi Blitar. In the future, this data can be used as a basis for the development of new motif designs in "Batik Kembang Turi" Blitar Gallery.
\end{abstract}

Keywords : batik, Blitar, Koi, motif

\section{ABSTRAK}

Batik Kembang Turi, Blitar hadir pada tahun 2018 sebagai perwujudan dari pelestarian batik di Kota Blitar. Galeri Batik Kembang Turi Blitar menjadi salah satu pusat pembuatan batik, sudah berhasil memberdayakan masyarakat sekitar untuk memproduksi batik dengan ciri khas Blitar. Namun hingga saat ini belum banyak masyarakat di luar Kota Blitar mengetahui keindahan dan keunikan batik Kembang Turi Blitar, padahal banyak potensi yang dapat dikembangkan untuk dapat meningkatkan kekuatan karakteristik dari batik Kembang Turi Blitar. Hasil dari penelitian ini berupa data dari 17 motif batik yang memiliki karakteristik motif utama yaitu Motif Kembang Turi dengan kombinasi dengan motif Koi, Gendang, Makam Bung Karno, dan Teratai yang merupakan ciri khas dari Kota Blitar. Ciri khas warna yang digunakkan pada batik Kampung Batik Kembang Turi, yaitu warna-warna yang cerah, seperti warna merah, hijau dan hitam yang merupakan ciri khas batik Kembang Turi Blitar. Ke depannya data ini dapat digunakan sebagai dasar pengembangan desain motif baru di Galeri "Batik Kembang Turi" Blitar.

Kata Kunci : batik, Blitar, Koi, motif

\section{PENDAHULUAN}

Di Indonesia, batik memiliki sejarah dan riwayat yang panjang, setiap wilayah memiliki proses membatik yang beragam mulai dari motifnya, proses canting dan warna yang digunakan. Terciptanya motif batik terjadi 
karena kebiasaan masyarakat yang sehari-hari melihat, meniru dan interaksi dengan kondisi alam sekitar dan berlangsung berulang, sehingga melahirkan ciri khas tertentu di setiap daerah. Ciri khas tertentu itulah yang telah mendarah daging dan diwariskan secara turun temurun yang kemudian kita kenal sebagai budaya daerah yang sering diistilahkan dengan penyebutan kearifan lokal (Anshori \& Kusrianto, 2011).

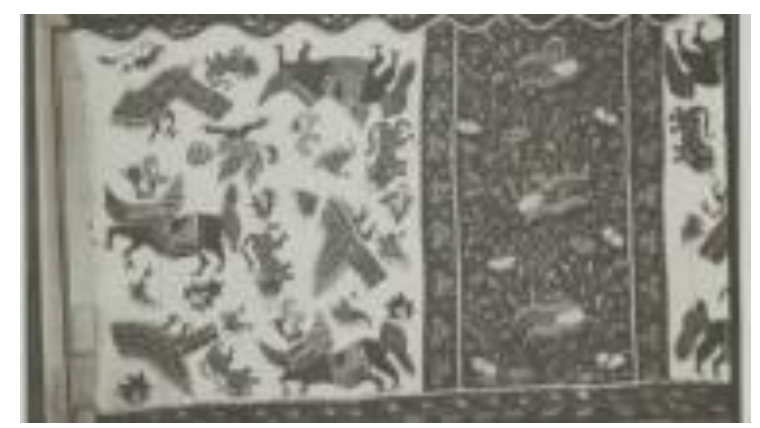

Gambar 1. Motif Batik Afkomstig Uit Blitar Koleksi Dewan Kesenian Kab.Blitar

(Sumber : Rahmanto Adi, Juli 2016)

Setiap Provinsi di Indonesia memiliki kain batik khas yang patut dibanggakan, salah satunya Kota Blitar. Blitar sendiri memiliki batik khas kebanggan, yaitu Batik Tutur. Pada awalnya batik ini dinamakan "Batik Afkomstig Uit Blitar,1902" yang berada di Museum Leiden, Belanda. Namun pada tahun 2007 baru disadari oleh masyarakat Blitar yaitu Wima Brahmantya selaku ketua Dewan Kesenian Kabupaten Blitar (DKKB) bahwa Blitar mempunyai batik khas peninggalan zaman dahulu. Bentukan motif batik tutur pada dasarnya berasal dari batik Afkomstig Uit Blitar. Pengembangan batik tutur (sebagai motif batik kuno asli Blitar) ke motifmotif lainnya merupakan upaya kreatif dalam bentuk reproduksi dengan konsep revitalisasi (Sari, 2018). Pada Tanggal 5 Februari 2012 DKKB beserta rekan-rekannya mengganti nama batik ini menjadi Batik Tutur dan resmi di publikasikan. Pada dasarnya "tutur" berasal dari kata "pitutur" dari teks Jawa kuno yang artinya nasihat, selain itu juga nama Batik Tutur diganti dengan alasan supaya masyarakat lebih mudah mengingat dan mengucapkan (Brahmantya, 2018).

Menurut Rochtri dan Zuraidah dalam penelitian berjudul "Transformasi Pesan Moral dari Dinding Candi Menjadi Sehelai Kain", Asal usul budaya batik di Blitar hingga saat ini masih menjadi perdebatan panjang. Kemungkinan batik Blitar berkembang karena mendapat pengaruh dari Keraton Yogyakarta ataupun Surakarta sebagai akibat adanya komunikasi dagang atau kewilayahan pada masa lalu. Pendapat lain mengatakan bahwa kemungkinan saat invasi Sultan Agung Hanyokrokusumo pada tahun 1633 ke wilayah timur Pulau Jawa (termasuk Blitar) hingga Blambangan, maka Batik Kraton Mataram Islam memengaruhi juga kesenian Blitar, sehingga lahirlah batik Blitar pada masa lalu (Gardjito, 2015).

Berdasarkan infoblitar.com, pada tahun 2018 dalam program Pemerintah Kota Blitar yaitu Program Masyarakat Berdaya Menuju Kota Pariwisata (Maya Juwita), Pemerintah Kota Blitar meresmikan Kampung Turi menjadi Kampung Batik Kembang Turi pada tanggal 2 Oktober 2018 sebagai salah satu upaya dalam melestarikan kearifan lokal serta upaya mengangkat ekonomi rakyat khususnya masyarakat Kelurahan Turi dalam katagori batik. Dalam situs blitarkota.go.id menyebutkan upaya mendukung dan meningkatkan kemandirian ekonomi yang berorientasi pada industri pariwisata dan ekonomi kreatif yg berdaya saing dan berwawasan lingkungan, pemerintah kota dan masyarakat Kelurahan Turi membuka galeri sebagai wadah untuk mengembangkan potensi dan menampung hasil produksi dari pembatik Kelurahan Turi. 
Pada saat ini batik Blitar khususnya di Kampung Batik Kembang Turi memiliki 2 ciri khas motifnya yaitu motif Koi dan motif Kembang Turi, motif tersebut terdapat dalam ragam hias flaura dan fauna dimana tumbuhan dan hewan menjadi inspirasi dalam pembuatan motif (Kudiya, 2019), memiliki maknanya tersendiri dan memiliki ornamen atau isen-isen yang hampir sama setiap motifnya, proses menyusun dan memadukan bentuk serta garis sehingga menghasilkan sebuh motif (Sehersono, 2006). Ciri khas dari motif utama Kampung Batik Kembang Turi ini dilihat dari setiap batiknya terdapat Motif Kembang Turi serta motif-motif pendukung merupakan motif khas Kota Blitar lainnya seperti Bunga Kembang Sepatu, Gendang, Bunga Kenanga, Belimbing, dan Bunga Teratai. Namun saat ini masih banyak masyarakat yang belum mengenal dan mengetahui Batik Kembang Turi khas Kampung Batik Kembang Turi. Melalui media ini diharapkan dapat membuat keberadaan batik Kembang Turi semakin dikenal oleh masyarakat pecinta batik.

\section{METODE}

Metodologi penulisan yang digunakan dalam artikel ini adalah menggunaka metode kualitatif melalui observasi dan wawancara. Adapun metode pengumpulan data sebagai berikut :

1. Studi literatur, merupakan hasil pengumpulan data yang diperoleh dari sumber literatur seperti buku dan jurnal ilmiah untuk memperoleh data mengenai batik Blitar, Kampung Wisata Batik Kembang Turi, tanaman Turi dan ikan Koi

2. Observasi lapangan, teknik pengumpulan data dengan mengadakan penelitian dan peninjauan langsung ke Kampung Batik Kembang Turi.

3. Wawancara, pengumpulan data yang dilakukan melalui komunikasi langsung dengan perangkat Kampung Batik Kembang Turi dan Asosiasi Batik Blitar Asli (ABABIL) yaitu : Pak Parianto selaku ketua dan Bu Eti Rohaeti selaku sekretaris Kampung Batik Kembang Turi serta Pak Nanang Pramdi selaku ketua ABABIL.

Alat-alat pendukung yang digunakan dalam pengumpulan data yaitu buku dan alat tulis, kamera, laptop dan handphone untuk media dokumentasi perekam pada saat melakukan wawancara.

\section{HASIL DAN PEMBAHASAN}

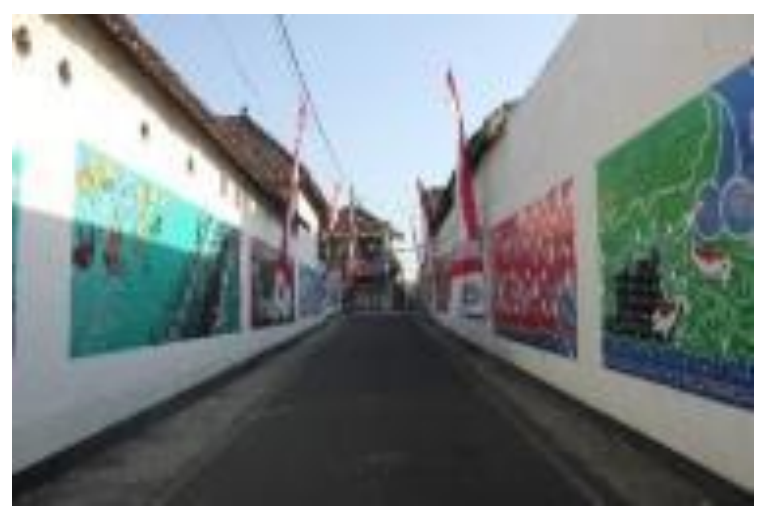

Gambar 2. Kampung Batik Kembang Turi (Sumber : Dokumentasi Penulis, 2019)

Kampung Batik Kembang Turi memiliki ciri khas pada setiap batiknya, dimana setiap batiknya terdapat motif batik Kembang Turi dengan visualisasi berbeda dan motif utama didukung dengan motif khas Blitar lainnya. Teknik pembuatan batik pada kampung batik kembang turi yang digunakan saat ini didapat dari hasil pelatihan yang pernah mereka ikuti, pelatihan yang diadakan oleh pemerintah perindustrian dan pelatihan dari Asosiasi Batik Blitar Asli (ABABIL). Dalam teknik pewarnaan, warna yang digunakan saat ini masih 
terpengaruh oleh adanya keterlibatan politik, yakni warna yang mendominasi seperti warna merah merupakan hasil dari keterlibatan politik di sana. Berikut motif batik yang berada di Kampung Batik Kembang Turi:

\section{a. Motif Batik Kembang Turi}

Motif khas dari Kampung Batik Kembang Turi adalah motif Kembang Turi dan Ikan Koi. Menurut Ibu Eti Rohaeti selaku sekretaris dari Kampung Batik Kembang Turi, filosofi dari Batik Kembang Turi sendiri sebatas nama desa dan menampilkan ciri khas dari Kota Blitar, tidak begitu mendalam. Namun, berdasarkan hasil wawancara dengan Bapak Nanang Pramadi selaku Ketua Asosiasi Batik Blitar Asli (ABABIL), filosofi dari motif batik Kembang Turi yakni, Tanaman Turi merupakan tanaman yang dapat hidup dimana saja dan Ikan Koi bermakna kebaikan.

Hasil dari penelitian ini berupa data 17 motif batik hasil produksi perajin Kelurahan Turi yang memiliki karakteristik motif utama, yaitu motif Kembang Turi dengan kombinasi ciri khas motif dari Kota Blitar. Selain itu dilengkapi pemaparan proses pembuatan batik di Kampung Batik Kembang Turi.

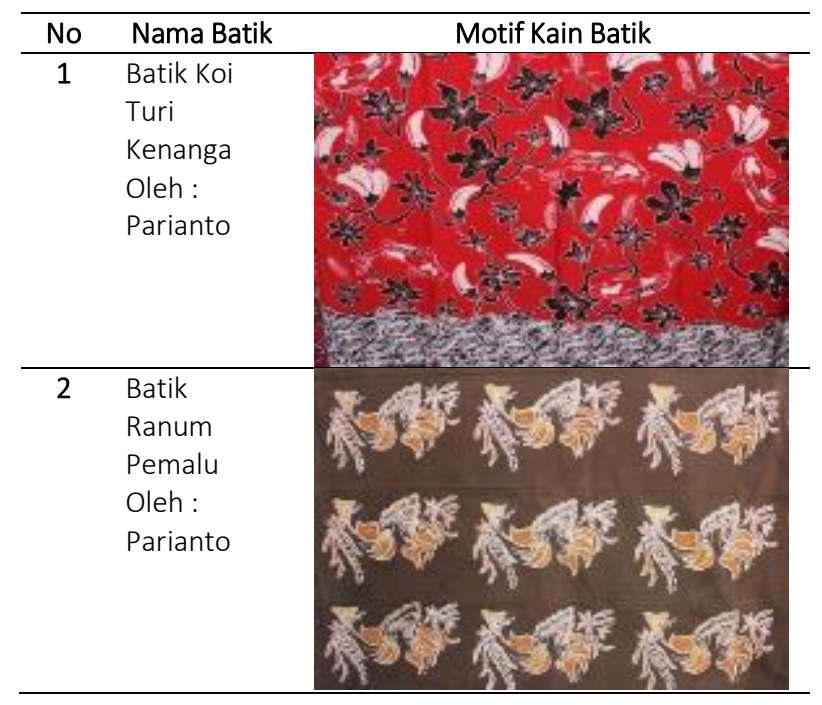

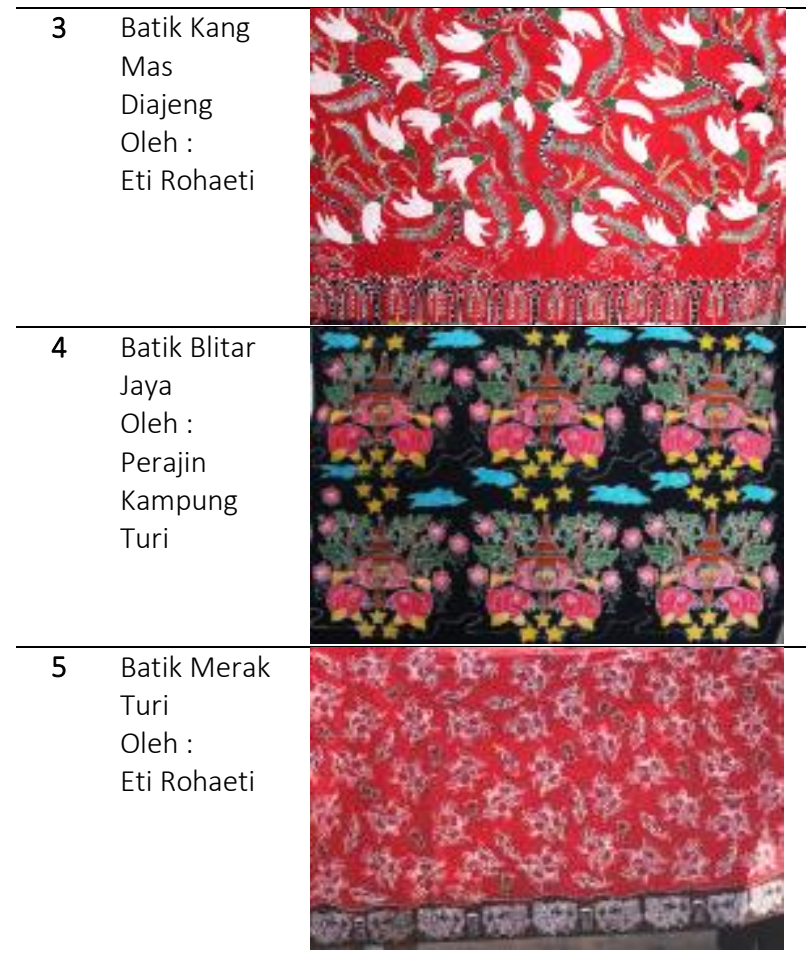

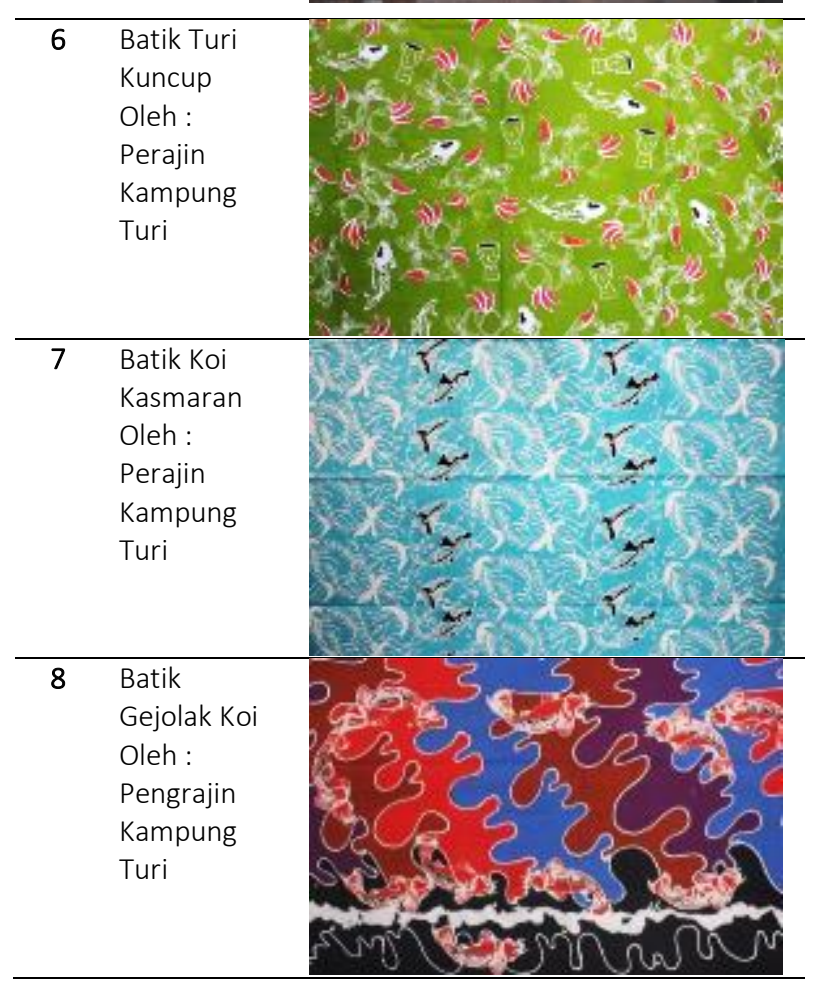



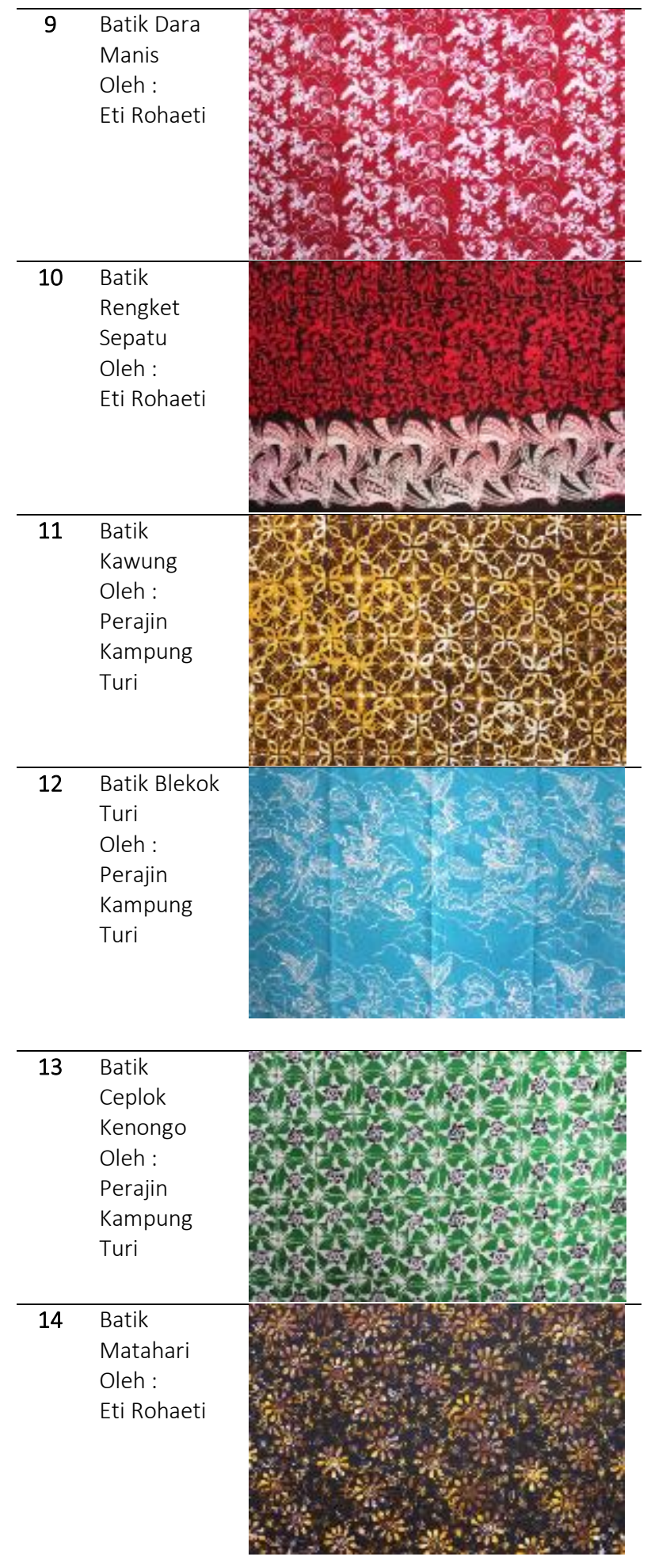

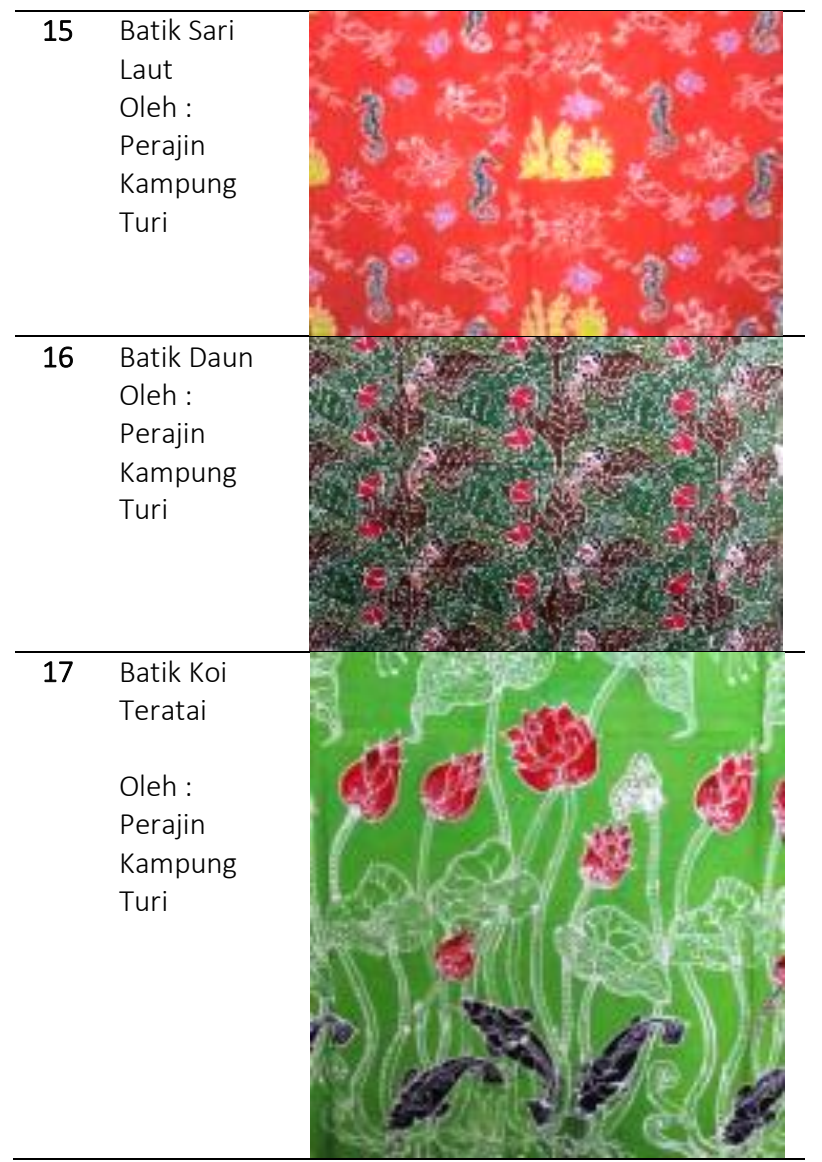

Tabel 1. Motif Batik Kampung Batik Kembang Turi (Sumber : Dokumentasi Penulisi, 2019)

Salah satu karya budaya yang banyak menggunakan unsur flora dan sarat dengan makna simbolik adalah budaya batik yang penggambarannya sudah distilasi sesuai maksud dan kebutuhannya (Sedjati, 2019). Hasil analisis motif batik Kampung Batik Kembang Turi pada tabel di atas menyimpulkan bahwa motif utama yang digunakan yaitu motif Kembang Turi dengan kombinasi Motif Koi, Gendang, Makam Bung Karno, dan Teratai yang merupakan ciri khas dari Kota Blitar sendiri, namun masih mengikuti bentuk asli visual asli dengan pengembangan yang sederhana dan dengan kompisisi pola motif satu langkah (single repeat). Teknik motif menggunakan teknik pengulangan satu langkah dengan komposisi motif kembang turi lebih dominan, 
dan tanpa ada isen isen pada motif. Dalam segi penamaan kain batik, nama batik dilihat dari motif yang terkandung pada kain batik atau penamaan dari pemesan kain batik itu atau juga dari menampilkan komponen motif khas itu sendiri. Elemen pendukung pada motif berupa elemen garis, dimana lebih banyak menggunakan elemen garis melengkung sebagai isen / pelengkap pada motif batik.

Motif batik merupakan bagian kritikal dari proses pembuatan batik itu sendiri, karena goresan canting dan gerak tangan pembatik juga melibatkan pikiran dan perasaannya (Suminto, 2015). Dalam hal inspirasi motif, perajin Kampung Batik Kembang Turi terinspirasi dari hal sekitar, lingkungan dan juga pengaruh dari permintaan konsumen. Segi pewarnaan, Kampung Batik Kembang Turi menggunakkan warna-warna cerah dan dapat disimpulkan warna yang paling sering digunakan ialah warna merah, hijau, dan hitam. Pewarnaannya menggunakan pewarna remasol dengan teknik colet.

\section{b. Proses Pembuatan Batik}

Sistem pembuatan batik di Kampung Batik Kembang Turi yang digunakan saat ini berdasarkan dari apa yang masyarakat dan perajin dapatkan waktu pelatihan yang diadakan oleh pemerintah. Proses pembuatan Batik Kembang Turi dilakukan dengan teknik motif square repeat (satu langkah), merupakan teknik sederhana dan paling dasar (kight, 2011), dengan teknik pewarnaan colet dimana bahan pewarna langsung dikuas pada permukaan kain (Gratha, 2012), dan pewarnaan menggunakan pewarna remasol dengan penguncian warna menggunakan waterglass.

Tahapan dalam proses pembuatan batik di Kampung Batik Kembang Turi masih dilakukan secara manual dan tradisional dan juga dikerjakan secara bersama-sama atau individu.

\begin{tabular}{|c|c|c|}
\hline No & Penjelasan & Gambar \\
\hline 1. & $\begin{array}{l}\text { Pembuatan Motif } \\
\text { Dalam pembuatan batik } \\
\text { tulis, teknik yang digunakan } \\
\text { yaitu dengan teknik single } \\
\text { repeat yaitu teknik satu } \\
\text { langkah dengan media } \\
\text { kertas. }\end{array}$ & \\
\hline 2. & $\begin{array}{l}\text { Dalam pembuatan batik } \\
\text { cap, } \\
\text { tahap awalnya yaitu } \\
\text { mengecap kain batik } \\
\text { dengan motif yang } \\
\text { diinginkan serta dengan } \\
\text { teknik penyusunan motif } \\
\text { sesuai pesanan (single } \\
\text { repeat atau abstrak) }\end{array}$ & \\
\hline 3. & $\begin{array}{l}\text { Proses Penakaran Warna } \\
\text { Pencampuran warna } \\
\text { dilakukan untuk } \\
\text { mendapatkan warna yang } \\
\text { diinginkan dengan } \\
\text { pengabungan warna primer } \\
\text { dan warna sekunder }\end{array}$ & \\
\hline 4. & $\begin{array}{l}\text { Proses Pewarnaan Detail } \\
\text { Proses pewarnaan detail } \\
\text { dilakukan menggunakan } \\
\text { teknik colet dengan media } \\
\text { cotton buds. Pewarnaan } \\
\text { menggunakan pewarna } \\
\text { remasol }\end{array}$ & \\
\hline
\end{tabular}




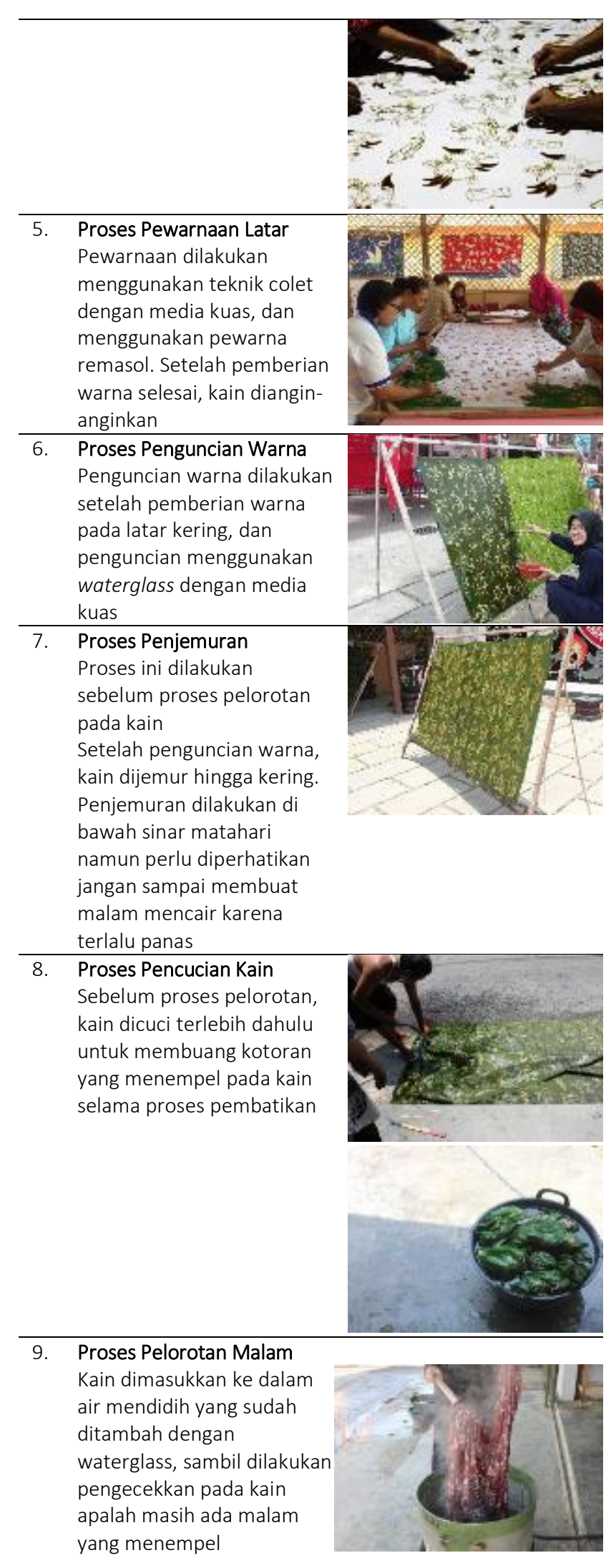

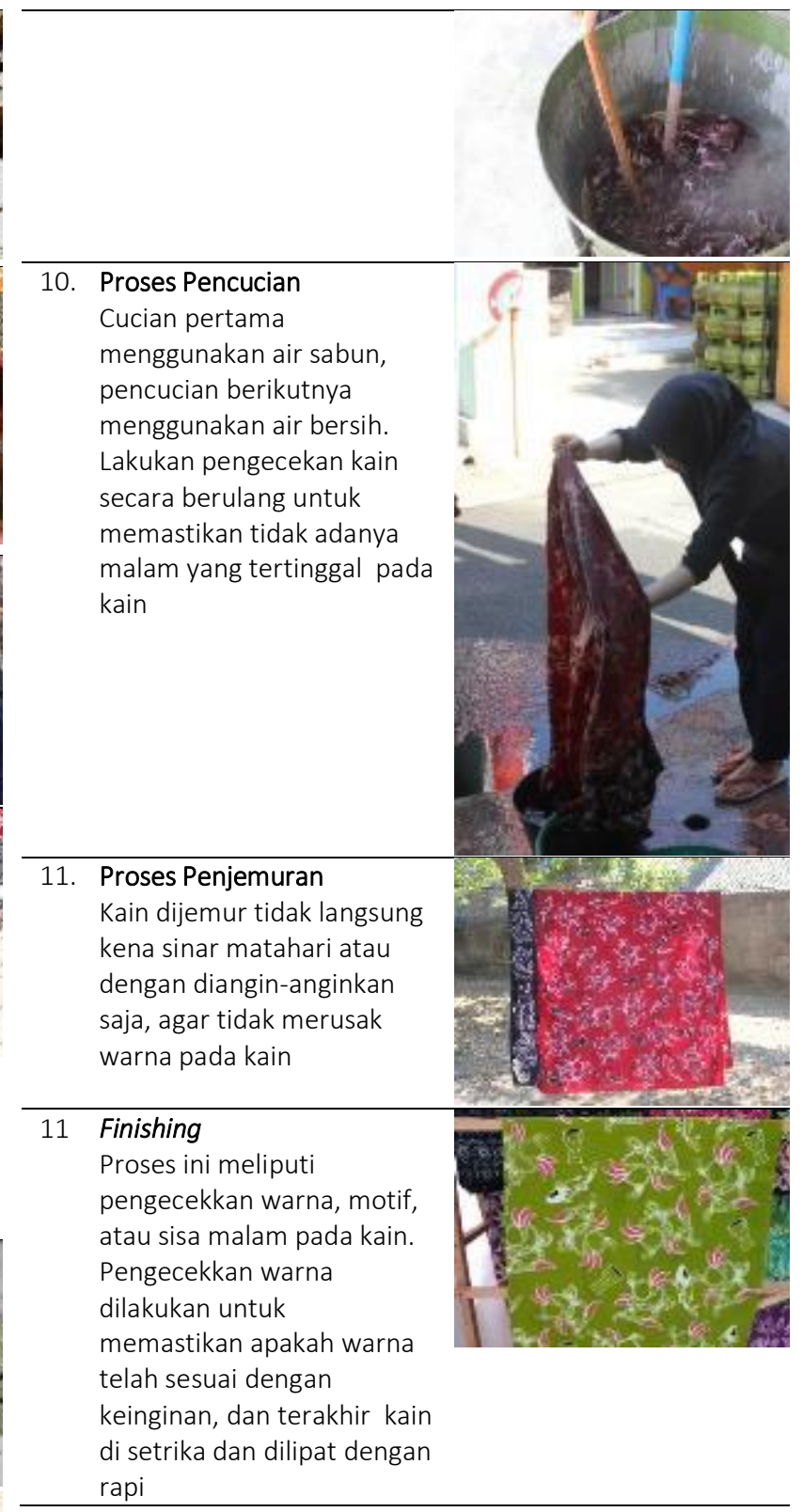

Tabel 2. Proses Membatik di Kampung Batik Kembang Turi (Sumber : Dokumentasi Pribadi , 2019)

\section{PENUTUP}

Kota Blitar mempunyai potensi besar dalam produksi batiknya, salah satunya yaitu Kampung Batik Kembang Turi. Kampung Batik Kembang Turi mempunyai motif khas, yaitu motif Kembang Turi dan juga motif Ikan Koi dengan kombinasi motif ciri khas dari Kota Blitar. Teknik pembuatan Batik Kembang Turi 
masih terhitung sederhana dan manual dari segi teknik pembuatan, pola motif, serta pewarnaan.

Kampung Batik Kembang Turi Memiliki potensi dalam mengembangkan batik Kembang Turi, pengembangan tersebut dapat meningkatkan eksistensi batik Kembang Turi. Potensi pengembangan motif batik Kembang Turi dapat dilakukan melalui pengolahan stilasi, pengembangan komposisi pola motif dan juga variasi pengolahan warna pada batik kembang Turi. Filosofi motif yang didapat, dari semua motif yang terdapat di Batik Kembang Turi memiliki filosofi yang mengakar pada ajakan untuk dapat hidup bermasyarakat dimana saja dengan kepribadian yang baik.

Penelitian yang dilakukan merupakan upaya pengenalan motif batik Kampung Batik Kembang Turi, upaya memberikan informasi tentang Batik Kembang Turi dalam jenis motif serta pembuatan batik di Kampung Batik Kembang Turi agar dapat menarik dan dapat mengenalkan batik Kembang Turi kepada masyarakat luas.

\section{Ucapan Terima Kasih}

Terimakasih disampaikan kepada Kampung Batik Kembang Turi khususnya kepada Bapak Parianto selaku ketua Kelurahan Turi, Ibu Eti Rohaeti selaku sekretaris Kelurahan Turi, dan Bapak Nanang Pramadi selaku Ketua Asosiasi Batik Blitar Asli (ABABIL) serta Masyarakat Kelurahan Turi yang telah bersedia meluangkan waktu dan membantu dalam penelitian ini.

\section{Daftar Pustaka}

Anshori, Y., \& Kusrianto, A. (2011), Keeksotisan Batik Jawa Timur, PT. Elek Media Komputindo-2011-ISBN: $\quad$ 978-602-001195-0.
Gratha, Benny. (2012), Panduan mudah Belajar Batik. Jakarta : Demedia Pustaka

Kight, K. 2011. A Field Guide To Fabric Design Book. Stash Book, Lafayette.

Kudiya, Komarudin. (2019). Kreatifitas Dalam Desain Batik. Itb Press Bandung

Megawati, D., Aryanto, H., \& Christianna, A. (2019). Perancangan Buku Batik Tutur Sebagai Media Promosi Bagi Masyarakat Blitar. Jurnal DKV Adiwarna, 1(14), 11.

Najib, M. A. (2018). Efektivitas Penambahan Suplemen Herbal Pada Pakan Ikan Terhadap Laju Pertumbuhan Dan Kelulushidupan Benih Ikan Koi (Cyprinus carpio linnaeus) (Doctoral dissertation, University of Muhammadiyah Malang).

Suminto, R. S. (2015). Batik Madura: Menilik Ciri Khas dan Makna Filosofinya. Corak: Jurnal Seni Kriya, 4(1).

Sedjati, D. P. (2019). KEBEN (BARRINGTONIA ASIATICA), MOTIF DAN PEWARNA BATIK. Corak: Jurnal Seni Kriya, 8(2), 98107.

Suhersono. (2006). Desain Bordir Motif Flora Dan Fauna Nusantara. Jakarta: Gramedia Pustaka Utama.

Wiranawati, N., Agustina, A., \& Nurhaini, R. (2017). Perbandingan Rendemen Dan Identifikasi Alkaloid Pada Bunga Turi Putih (Sesbania Grandiflora, L Pers) Dengan Bunga Turi Merah (Sesbania Grandiflora, L Pers) Dengan Metode Soxhletasi. Cerata Jurnal Ilmu Farmasi, 7(1).

\section{Webiste/laman:}

Kampung Batik Kembang Turi Terima Kunjungan Disbudpar Kota Blitar. Retrieved June 20 2020. From http://visitblitar.com/berita-pariwisata/detail/ Kendita Agustina, Kembang Turi Yang Kaya Manfaat, Good News From Indonesia, 02 Juli 2019 14.10 Wib Surabaya Jawa Timur

Resmi Monumen Batik Kembang Turi Di Kota Blitar. Retrieved June 20, 2020, From https://infoblitar.com/

Wakil Walikota Blitar Resmikan Kampung Batik Kembang Turi, Dinas pariwisata dan kebudayaan pemerintah kota Blitar, Blitar, from https://visitBlitar.com 2018-10-03 12:27:53 